\title{
Lived Experience of Women Suffering from Breast Cancer about the Meaning of Life: Evidences from the Society of Iranian Women.
}

\section{Leila Mokhtari}

Urmia University of Medical Sciences School of Nursing and Midwifery https://orcid.org/0000-00028527-9703

\section{Aram Feizi}

Urmia University of Medical Sciences

\section{Hamid Reza Khalkhali}

Urmia University of Medical Sciences

Abdollah Khorami Markani ( $\boldsymbol{V}$ khorami.abdolah@gmail.com )

Urmia University of Medical Sciences https://orcid.org/0000-0001-9318-8249

\section{Keywords:}

Posted Date: November 16th, 2020

DOI: https://doi.org/10.21203/rs.3.rs-108180/v1

License: (c) (i) This work is licensed under a Creative Commons Attribution 4.0 International License.

Read Full License 


\section{Abstract}

The authors have requested that this preprint be removed from Research Square. 